\title{
The Value of Integrated Multimodal Traveller Information and its Potential Contribution to Modal Change
}

\author{
Susan Kenyon and Glenn Lyons \\ Transportation Research Group, University of Southampton, Highfield, \\ Southampton SO17 1BJ. UK
}

\begin{abstract}
This paper reports on research that introduced the concept of Integrated Multimodal Traveller Information to mixed mode and mixed socio-demographic groups of travellers. Travellers were shown information about travel by car, coach and train for a journey with which they were familiar. Different levels of information were shown at different times, ranging from simple financial cost and journey duration information to information incorporating comfort and convenience factors. The research illustrates that the majority of travellers do not consider their modal choice for the majority of journeys. Rather, this choice is automatic and habitual, based upon subconscious perceptions of the viability and desirability of travel by modes other than the dominant mode. Thus, information about alternative modes is rarely consulted and travellers can be unaware of viable modal alternatives for their journeys. Results suggest that presentation of a number of modal options for a journey in response to a single enquiry could challenge previous perceptions of the utility of non-car modes, overcoming habitual and psychological barriers to consideration of alternative modes. Where the information presented incorporates comfort and convenience factors, in addition to cost and duration, it may challenge travellers' concerns about alternative modes and could persuade a modal change.
\end{abstract}

Keywords: habit, subjective, reasoned; integrated information; mode choice 


\section{INTRODUCTION}

Governments world wide are seeking to tackle the ever-rising levels of car use amongst their populations. In their armoury are a variety of 'push' and 'pull' measures (Steg and Vlek, 1997), to tempt and tug people out of their cars, respectively. Of the former, fiscal measures could force people not to travel by car, or to travel by car less; of the latter, softer measures, which hope to persuade the car user to consider modification to their behaviour, including improvement in alternatives - and improved information. The information is both of a marketing (Wright and Egan, 2000) and a more practical, 'how to' nature (for an overview, see Lyons et al, 2001), both aiming to promote travel by public transport, or by non-motorised alternatives to the car.

Despite research efforts in both the technical delivery and accessibility of traveller information (reviewed by Alder and Blue, 1998; see also Bolelli et al, 2000; White, 2000; and with regard to accessibility, Kenyon et al 2001) and in the development of content, both marketing and enabling in nature, which is relevant to user needs (e.g., Gillam et al, 1999; Kenyon et al, 2000; Lyons, 2001; Mehndiratta et al, 1999; INFOPOLIS, 1999), there is little evidence to suggest that the provision of information has been effective in promoting modal shift (e.g. Lappin, 2000; Yim et al, 1996). The conclusion has often been that the information provided has not been effective technically, nor is it providing the content that users need to make their modal switch. Thus, further research continues in these two areas. In the former, the focus is upon advanced traveller information systems (ATIS), which can enable the provision of personalised information, to a variety of devices, tailored to the individual needs of the traveller, with a move towards intelligent traveller information systems (ITIS), which employ artificial intelligence to enable, for example, the automatic gathering and presentation of information prior to user request (Adler and Blue, 1998). 
With regard to information content, the focus has been upon the identification of a number of costs to the traveller and the consequent provision of information about these costs, to overcome barriers to modal change, the causality of which, it is assumed, in part at least, is ignorance or misinformation. For example, concern about financial cost is a barrier to modal change until the user is informed about reduced fares; or reliability is a barrier, until the user is presented with information which either counters claims that alternative modes are unreliable, or informs the user about delays, allowing the user to better manage their journey.

These can be termed instrumental-reasoned barriers to modal change (Steg et al, 2001). Information providers assume that users make reasoned choices between and behave rationally when considering alternative modes, making a rational trade off between the costs and benefits of travel by each mode. Thus, if information about the true costs and benefits are revealed, travellers would choose to travel by the most cost-effective mode, where 'cost' is seen to encompass factors including comfort, convenience, financial cost, journey duration and reliability (Ortuzar and Willumsen, 1994; Transportation Research Group, 2000).

The hypothesis that the provision of (the means of access to) information about a number of modal options will lead users firstly to access, secondly to compare information about and thirdly to make a rational choice between each mode underlies the provision of traveller information as a tool in transport policy (DTLR, 2001; Yim et al, 1998). However, some studies have suggested that there are more significant psychological barriers to the effective use of information, which move beyond the above concerns. These barriers relate to the role of habit in modal choice (Aarts et al, 1997; Thorgersen, 2001; Verplanken et al, 1997); and the presence of symbolic-affective motives behind modal choice (Steg et al, 2001). These can not only affect the 
acceptance and use of the information that is provided, but they can actually prevent the user from seeking the information about alternative modes.

It is suggested that the role of habit in traveller behaviour is such that modal choice is rarely the result of reasoned action, even when a novel journey is to be undertaken. Rather, modal choice becomes an automatic and, to an extent, a mindless 'decision', regardless of the journey characteristics. One no longer weighs the pros and cons of an habitual modal choice, nor checks ones attitudes towards the choice (Aarts et al, 1997), thus information is ineffective, in two ways. Firstly, the modal choice is, more precisely, routine and as such, information will not be consulted, because modal choice is not considered. Secondly, the independence of habit from attitude suggests that promotional information will be ineffective.

\begin{abstract}
'A habit is a learned sequence of acts that have become an automatic response to specific cues [e.g, 'I need to travel'] and are functional in obtaining certain goals... Consequently, habitual choices of modes of transportation, for instance, are independent of the actor's attitude... This is an important reason why persuasive communication generally has had little success in changing transport behaviour'.
\end{abstract}

(TRIP, nd).

'Symbolic-affective motives' underlying modal choice are those that relate to 'high level needs' from transport (URS et al, 2001), broadly, how the mode makes one feel. Thus, the mode is attractive or unattractive because of the way it makes one feel about oneself and the way in which one is, or one believes one is, perceived by others as a result of one's modal choice. In this sense, the car has become the mechanical embodiment of desirable attributes, including modernity, progress, freedom, individuality, autonomy and empowerment (Aird, 1972; Flink, 1975; Freund and Martin, 1993; Gartman, 1994; Steg et al, 2001; Stradling, 2002; Tertoolen et 
al, 1998; Wright and Egan, 2000), providing an important means of communication about oneself and an identity for oneself in a society where 'what one has' is seen to be 'what one is worth' (Sachs, 1992:147).

The 'halo effect' of travel by car is such that the properties of the car are seen to be transferred to the traveller. Thus, whilst travelling by car, the traveller is seen, by others and by their self, to embody the features outlined above. When travelling by non-car modes, the reverse is true. As the characteristics of the mode are reflected from the mode to the self, the user is persuaded, both consciously and subconsciously, to choose the mode that makes them feel more powerful and superior, in preference to those which, they perceive, remove control, independence or opportunity for self-expression. In questioning modal choice, one is seen, in a sense, to question these factors and values. These symbolic functions of the car are present at both the societal, or cultural level and the individual, psychological level, influencing modal choice at a level that, to date, has remained largely untouched by information- and marketingoriented attempts to affect modal change.

In the light of the three groups of factors influencing information uptake, information use and modal choice - instrumental-reasoned factors, habitual factors and symbolic-affective factors - it can be suggested that current information provision, in seeking to tackle, in the main, only the factors within the former group, has fallen short of that necessary to promote modal change.

This paper reports on research which has sought to test the hypothesis that the provision of information about a number of modes, within a single enquiry, could help to overcome some of the barriers to information uptake, information use and modal change that exist as a result of habitual and instrumental-reasoned attitudes towards modal choice. The possibility that the 
information could address some symbolic-affective barriers is also raised. The paper begins with an outline of three different types of traveller information, providing a context to this research. The paper then presents an overview of the methodology, before discussing the results of the study. The paper closes with a discussion of the possible implications of the research, alongside recommendations for further studies in this area.

\section{UNIMODAL, MULTIMODAL AND INTEGRATED MULTIMODAL TRAVELLER}

\section{INFORMATION}

In this research, we distinguish between the following three types of traveller information provision. It is suggested in this research that each information type is likely to be used by identifiable user types, to be used in defined ways for distinct purposes and, therefore, to have different effects upon the user.

Unimodal traveller information (UTI) is that which is provided within a particular information service, relating to a single mode of travel. Examples of UTI range from low tech paper timetables and road atlases, to dynamic itinerary planning facilities or real time service information, such as congestion monitoring, information about road works, or bus tracking, available to end users via CD-ROMs ${ }^{1}$, the Internet ${ }^{2}$, the telephone ${ }^{3}$, or at the interchange itself ${ }^{4}$.

\footnotetext{
${ }^{1}$ For example, Microsoft Autoroute, TravRoute and Route Planner.

${ }^{2}$ There are many web sites offering both static and real time journey planning information, for many modes. For example, UK rail information is provided at web sites including www.railtrack.co.uk and www.thetrainline.com; information to plan UK travel by coach at www.gobycoach.com, www.greyhound.com in the USA; bus information at, for example, www.firstbadgerline.co.uk, with real time information for Seattle (USA) at busview.its.washington.edu/busview_launch.jsp; and road-based information at www.theaa.co.uk in the UK, or www.wsdot.wa.gov/PugetSoundTraffic in the USA. All URLs correct at April 2002.

${ }^{3}$ The most popular UK UTI telephone service is the National Rail Enquiries Service (08457 484950), operating nationally since October 1996 and now receiving, on average, 5 million calls per four week period, peaking at 11 million calls/4 weeks during a time of major disruption to the rail network in October 2000.

${ }^{4}$ Whilst real time information has been available at the rail station for many years, it is only recently that passengers waiting at bus stops have been able to access this information, via displays such as those provided by NextBus (www.nextbus.com) in the USA and the UK.
} 
UTI may integrate information about a number of operators, but it is limited to providing information about a single mode.

Seeking information about a number of modal options using UTI can be an arduous process for the enquirer, not only requiring time-consuming consultation with a number of different sources but also prior knowledge of these sources, plus the desire to both travel by and to seek information about an alternative (non-habitual) mode. Thus, there are a number of cognitive barriers which must be overcome before the user will choose to use UTI to inform a modal choice: the decision to consider an alternative mode; desire to use an alternative mode; seeking information about information sources; and using and compiling information about the viability of a variety of modes. The effort involved in this process, combined with the uncertainty that the effort will be rewarded by the exposure of a viable modal alternative, is such that UTI is unlikely to be used to inform travel by alternative modes (for a discussion of the role of effort as a barrier to modal shift see Stradling, 2002; also, Potgraven and van Leusden, 1995). Thus, in seeking this information, it can be suggested that the UTI user has, in the main, decided on their mode of transport and is seeking information about their chosen mode to facilitate or support their journey by their habitual mode.

This conclusion has led information providers to consider the provision of multimodal traveller information (MTI) - the provision of information about more than one mode of travel, within a single source. MTI services are, in effect, a series of UTI services housed together, within a single web site, or available via a single telephone number. For example, the London Transport web site in the UK provides access to information about buses, the underground, river and light rail services, via a single web site; and Nottingham Travelwise, which provides access 
to itinerary planning, real time and static information to help users travel by both public and private transport modes ${ }^{5}$.

The principal underlying the provision of MTI services is to provide, in effect, a portal to traveller information, providing a single point of access to multiple sources of information, making information about the available modes more accessible and, consequently, reducing the effort associated with the search for information about travel by a number of modes using UTI. The hypothesis driving the provision of information has, as mentioned, been in response to the identification of instrumental-reasoned barriers to modal change - that the provision of the means of access to information about the true costs of travel by a number of modes will lead users firstly, to access and secondly, to compare, information about these modes, resulting in a rational and informed modal choice. In this way, the provision of MTI to travellers has been seen to be an effective way to encourage modal change, in contrast to UTI, which could in fact reinforce modal choice, being used primarily to reduce the uncertainty of the trip by the chosen mode (Egeler, 2002; Lappin, 2000; Schultz et al, 1999; Yim et al, 1996).

Whilst MTI services are multimodal in the sense that they provide a centralised means of access to information about multiple modes, there is typically no interaction between the information about each mode. Thus, MTI tackles only one of the four barriers (identified above) to the use of traveller information to inform a modal choice, rather than to merely inform travel, by the already-chosen (habitual) mode. Whilst MTI provides access to the sources of information for a number of modes, it fails to reduce user effort, for the user must still actively seek information about each mode, via separate enquiries; and it fails to promote the consideration of alternative modes. Indeed, despite the fact that results from some pre-

\footnotetext{
${ }^{5}$ Web sites are at www.londontransport.co.uk, utc.nottscc.gov.uk/index.htm. Similar sites exist in the USA, for example, www.travinfo.org, www.smarttrek.org and 511, the national telephone number for (local or state-wide)
} 
implementation studies into user attitudes towards MTI have suggested that users would respond to such information with rational consideration of modal choice and thus a modal change (Harris and Konheim, 1995; Neuherz, 2000), a significant modal shift in response to MTI has not been observed to date (Abdel-Aty et al, 1996; Lyons et al, 2001). Thus, it is suggested in this research that the majority of MTI is used in the same way as UTI - as information that facilitates or supports travel by the mode that has been selected before the information is consulted.

The integration of MTI could, this research suggests, overcome the barriers to the use of MTI to inform modal choice. Integrated Multimodal Traveller Information (IMTI), as with MTI, provides information about more than one mode of travel within a particular information service. However, in contrast to MTI, IMTI provision automatically presents the user with information concerning different mode choice options in response to a particular journey specified by the user. For example, where the user enters the single enquiry

Travel from: Banbury, Oxfordshire (UK)

Travel to: Southampton, Hampshire (UK)

the IMTI service would provide information about the journey by (for example) rail, coach and car, on a single screen, or sheet of paper. Whilst an MTI service might provide access to the same information, the onus is on the user to assemble the comparative information for different modes. IMTI minimises the effort for the user in acquiring information on mode choice options and is able to expose the user to information on such options even if they had not intended to consider or review a mode choice decision when accessing the service. In this way, IMTI has the potential to address all four of the potential barriers to the use of information to inform a multimodal traveller information. 
modal choice. The user need not decide to consider an alternative mode, or desire to use an alternative mode, before information about alternatives is presented; and the user need not seek information about alternative sources, nor expend effort compiling information about each mode.

In this sense, this paper suggests that integrated multimodal traveller information, where a number of modal options for a journey are presented to the user following a single enquiry, may be more effective in challenging perceptions and ignorance and, in turn, persuading a modal change, reducing as it does the effort associated with locating and comparing information about alternative modes, whilst also promoting the suggestion of modal alternative, bypassing habitual, instrumental and subjective barriers to consideration of modal alternative.

\section{METHODOLOGY}

A series of focus groups were undertaken across England, to assess the potential demand for, user needs from, the potential barriers to the use of IMTI and its potential effects. The groups were undertaken within an eight-day period, to minimise, as far as possible, differential influence of external events. The composition and location of each focus group is detailed in Table 1.

Table 1 inserted here.

Locations were selected in light of their position on the road network and the quality of the transport infrastructure for both local and long distance travel, with the additional objective of providing an urban/rural mix. Each focus group was designed to represent a sector or a combination of sectors of the UK population and all groups contained a mix of those who primarily are either car and public transport users. It was considered important to consult a 
broad demographic mix of participants, to ensure that travellers in all life stages were represented and to enable consideration of the influence of factors including age, gender, family profile and modal choice upon travel behaviour and receptivity to IMTI. Whilst some conflict was introduced with regard to modal choice, care was taken to ensure, to the best of our ability, that participants would feel comfortable with fellow group members and conflict outside of modal choice was minimised. Participants were recruited on-street by an external agency, in compliance with standards specified by the UK Market Research Society, to a specification provided by the authors. Participants received an incentive payment, in addition to reimbursement of travel costs. The groups were either singly or jointly moderated by the authors and no observers were present.

The discussions firstly aimed to highlight and expose the modal choice and travel behaviour of participants and to understand the decision making process informing current modal choice, specifically the user-perceived constraints on modal choice and the current use and influence of information upon travel behaviour and modal choice. The concept of IMTI was introduced towards the second half of the discussion. Participants were invited to discuss the concept, after which sample IMTI was presented.

Participants were presented with three forms of IMTI, in stages. An example of each information stage is presented later in this paper. The visual aids were personalised to each focus group location, providing information for a real middle-distance journey to a location with which they were likely to be familiar. All information presented within the visual aids was factually correct at the time the groups were held. Familiarity with the journey allowed informed discussion which would not have been possible if an abstract example were used. In addition, participants were likely to have a fully formed travel strategy to reach this destination, ensuring 
that the role of habit in modal choice could be explored. Each stage contained progressively more detailed information for travel by car, coach and train and participants were asked to discuss their reactions to the information. In particular, the authors sought to monitor the extent to which the information confirmed or challenged participants' prior perceptions of the modes. Before the information was presented and following examination and discussion of each stage of the information, participants were asked to (re)state which mode they were likely to use to undertake the specified journey.

The research took a qualitative approach to the issues, to allow the authors to probe, in depth, attitudes towards and motivations underlying travel choices and the role of information in challenging these choices. In designing the research, the authors had concluded that a more quantitative study would fail to uncover reasoning behind travel choices to the depth required and was, at this stage, premature. The focus group approach allows free discussion of a multitude of issues, to a great extent avoiding the researcher-imposed constraints inherent in structured interviewing or questionnaire surveys. In addition, it was decided that a quantitative approach, introducing IMTI as intervention in travel choices, for example, employing activity diaries, was premature at this stage. Rather, attitudinal studies to allow a preliminary examination of the viability of the proposed information system and to understand the correct information structure would be more appropriate. This quantitative approach would be suitable in further studies in this area. However, we would draw attention to some potential problems in using this methodology. These are considered in the discussion section, later in this paper.

This paper now turns to discuss the findings of the focus group discussions, presenting discussion of modal experience and current travel choices, highlighting the role of habit in participants' travel choices; and attitudes towards different modes, highlighting the presence of 
both reasoned and subjective attitudes. The paper then turns to consider current awareness and use of traveller information; and reactions to the concept and presentation of examples of IMTI.

\section{FINDINGS}

\section{Modal experience and current travel choices}

The role of habit in modal choice emerged strongly and naturally, confirming the findings of previous studies, mentioned above. Participants were found to be highly habitual in their travel choices, on two levels: in terms of their trip types (destination and purpose) and their modal choices for these trips.

Participants are highly habitual in their daily routines, performing the same tasks on a daily and weekly basis: for example, commuting, taking children to school or to extra-curricular activities, visiting friends and family, or undertaking voluntary work. Strong habituality in modal choice was evident, if slightly variable, regardless of age, gender and family circumstances. The majority of travel is as part of this fixed routine and, as such, the majority of trip types are fixed, with the majority of journeys being familiar, made regularly and for a stated purpose. Even during 'leisure time', participants tend to follow an habitual pattern of activities, governing, for example, when and where to go shopping or to go out in the evenings - and how

to travel. Modal choices are rarely considered for these familiar journeys, having become so habitual that they are performed automatically and without thought.

Participants' modal identity is firmly fixed within their minds, contributing towards their reluctance to consider alternative modes. Most participants describe themselves as either car drivers or public transport users. The fact that few participants use the car or non-car modes alone, with the majority regularly using at least one other mode, reflects the importance of modal 
identification and participants’ psychological attachment to the mode, highlighting and reflecting their subjective attitudes towards different modes. It was also observed that participants identify some trip types as 'car journeys' and some as 'public transport journeys'. Thus, even for unfamiliar trips, the modal 'genre' is decided subconsciously, based upon preconceptions of the desirability of undertaking the journey by each mode. Participants also tend to have a 'primary' and a 'default' mode of transport, the former representing the automatic, or habitual, modal choice for the majority of journeys, the latter being considered when travel by the primary mode is ruled out - for example when the traveller would be drinking alcohol and unable to drive, or if the car were being serviced.

The habitual nature of participant lifestyles and thus travel and the subconscious, selfrestricted nature of modal choice, the result of which is the lack of consideration of the full range of modal choices, was common for both car and public transport users.

\section{Attitudes towards public transport and the car}

Participants discussed both habitual, practical and emotive reasons behind modal choice. They naturally expressed strong and deeply held attitudes towards all modes of transport. It emerged that negative opinions of public transport are more fully formed than positive opinions of the car. Many expressions of the positive aspects of travel by car emerged as criticisms of travel by public transport; and perceptions of public transport were strongly linked to views of travel by car. Negative perceptions of public transport were often qualified by a positive perception of travel by car and vice versa. However, very few perceptions are informed by experience, or by traveller information. Rather, much is assumed. 
Many participants, most notably, those who are not regular public transport users, perceive public transport to be inconvenient; unreliable; uncertain, risky and unsafe; time consuming; costly; and incompatible with their lifestyle, in both practical and more subjective terms. The inconvenience of public transport, in particular the impersonal nature of public transport and difficulties in meeting individual travel needs, was frequently cited by participants as a significant barrier to its use. The perceived inability of public transport to facilitate door to door travel; problems in trip-chaining, increasingly a transport need, particularly for employed people with dependants (a growing proportion of the workforce) and with dispersal trends in land use; and a lack of integration of services, the result of and resulting in inconvenient timetabling, infrastructure and routes, resulting, in turn, in discomfort and increased journey time, were frequently cited as barriers to public transport use - and as reasons to use the car. The difficulty associated with travel by non-car modes because of the planning involved in each journey, made more troublesome by the lack of co-ordinated information sources and a lack of familiarity with information sources, plus unfamiliarity with public transport use, was contrasted with travel by car, which, for the majority of travellers, involves little planning or forethought and is familiar and, therefore, psychologically more comfortable. Participants expressed perceptions of travel by car as the reverse of the perceptions outlined above: as convenient, timely, flexible, enabling travel that is independent of timetable restrictions and fixed routes.

Practical, reasoned perceptions of each mode combined in discussion with more subjective perceptions. In particular, travel by car is seen to give freedom and control over individual mobility: over direction, route, departure and arrival times, journey duration and speed. Whilst there are rational reasons behind these desires, in part detailed above, more emotive reasons were also given, as travel by car was contrasted with feelings of powerlessness 
and loss of control when travelling by public transport. These more ideological motivations behind car use appear to be intrinsic and subconscious. They are rarely acknowledged by participants and thus remain largely unchallenged.

It emerged that the strength of both reasoned and subjective attitudes was directly correlated to participants' experience and use of public transport. Regular users of public transport held more positive opinions of the services and infrequent users, more negative perceptions. However, causality of these opinions was unclear. This observation could suggest that barriers to public transport use could be overcome through actual use; or it could just be that those with more favourable attitudes towards public transport are naturally more predisposed to use of this service. Additionally, the strong correlation between frequent use and living in an urban area with a good public transport network could indicate that perceptions of public transport are related to the level of service and the level of awareness of service in the locality, in addition to the level of use.

The frustration of dedicated public transport users in the face of ideological and assumed negative perceptions of public transport was evident, as they challenged the positive views of the car, citing negative environmental, health and social costs of over reliance upon the car. These views, once expressed, were not refuted by any participants and for some participants, raised awareness of these externalities was sufficient to persuade consideration of a modal change, for some journeys, highlighting the possible role of targeted marketing of public transport and demarketing of the car (Wright and Egan, 2000). Travellers with children were more susceptible to consideration of the negative impacts of car travel than those without. Young travellers were least concerned about the externalities, perhaps surprisingly, given that the younger age group are often stereotyped as being environmentally aware and socially concerned. 


\section{Current awareness and use of traveller information}

The discussion exposed a number of barriers to traveller information use. Firstly, there is a lack of awareness of the types of information available from formal information sources - for example, that more than static timetable information for public transport can be obtained. Secondly, individuals exhibit a lack of awareness of their current use of information, particularly information for travel by car. Much of the information used for travel by car is information that the users have not actively sought, but have passively absorbed: on the radio, by the roadside, or by word of mouth. This information is unconsciously received and is not viewed as information, but as knowledge. This perception of an information imbalance contributes to the perception that travel by car is simpler than travel by public transport and is a key barrier to public transport use, adding weight to the perception that travel by public transport is difficult and inconvenient. The desire for easy to access, integrated information about a variety of modes naturally emerged, unprompted, in response to the discussions regarding the difficulties in accessing information about travel by public transport. The simplification of the information seeking process could, participants suggested, lead to increased awareness of the travel options for each journey and could, perhaps, lead to increased consideration of and, possibly, increased use of, public transport.

Thirdly, there is a perception that accessing information is difficult and time consuming, due in part to, fourthly, the lack of awareness of information sources. Lack of information about information sources creates a 'three step' planning task for travel by public transport, again acting to reinforce the difficult nature of travel by public transport. (1), participants must find out about the information source; (2), they find out whether they can make the journey by the 
public transport mode (if it is not possible to make the journey by this mode, the process will begin again); (3), they find the relevant information to facilitate their journey. In contrast, when travelling by car, participants need only take the latter of the three steps, if planning at all, often relying upon in-trip information - road signs, or human/technological in-car navigation systems.

These barriers can be seen as a key failure of existing information provision. The existence of these barriers act to reduce the likelihood of information access and thus the efficacy of existing information provision acting, in interaction with the observed barriers to consideration of modal choice, to reinforce habitual choice of the primary mode of travel. This process is detailed in Figure 1.

Figure 1 inserted here.

Integrated multimodal traveller information

\section{Visual aid 1}

Following the more general discussion regarding the use and usefulness of traveller information, participants were formally introduced to the concept of integrated multimodal traveller information - an information service which would produce an itinerary for a journey by three modes of transport, as the result of a single enquiry. Participants were then shown a series of visual aids, each depicting the journey options in progressively increasing detail. Visual aid 1 is reproduced as Figure 2, showing information about cost and journey duration for a middle distance journey, by car, coach and train. Participants were given the space to discuss their reactions and the authors were keen to observe interactions with the information on a number of levels, in particular: the extent to which reactions were polarised by individual or modal 
characteristics; the extent to which (and why) the information was welcomed or rejected; and the stated effect of the information on modal choice.

Figure 2 inserted here.

Participant reactions to this information were both positive and negative. There were no noticeable differences according to personal characteristics. However, responses did differ along modal lines and perspectives were observed to be coloured by (previously expressed) subjective attitudes. Dedicated car drivers demonstrated scepticism and initial hostility, whilst less dedicated car drivers and public transport users expressed a higher degree of interest. A number of participants reacted defensively when presented with the information, feeling that the supply of information about alternative modes represented not a suggestion of a modal alternative, but a modal challenge. Many of these participants internalised this feeling of being challenged. These participants continued to assert their right to travel by car, in the face of a perceived threat to this right. This reaction declined with discussion and debate - however, it is one that may prevent objective assessment of the information and may be a barrier to acceptance of the concept and the use of IMTI.

Visual aid 1 began to challenge prior perceptions regarding financial cost and journey duration, challenging assumptions that the car is the optimal mode for the journey in these (cost and time) terms. Importantly, the information raised awareness of alternative modes, informing the traveller that it is possible to make the journey by different modes. A small number of participants suggested that this awareness alone could be sufficient to prompt a modal change and the perceived benefits of IMTI were expressed during the discussions: 
- It makes you think. It would make me think of the alternatives.

- It's definitely better to have the information together because I wouldn't bother to phone up the train company and the coach company and I certainly wouldn’t sit down and work out how many miles per gallon my car did and stuff. But just to give you a rough idea.

However, because the information did not consider the costs of the complete door to door journey, some participants felt that the calculations were misleading, reducing trust in the information and prompting participants to question the motive of the information provider. There was also suspicion regarding information accuracy and it was suggested that the information was purposefully inaccurate, as part of a campaign to persuade travellers to travel by non-car modes. This high level of suspicion regarding the motive of the information provider again highlights the concern, amongst some participants, that the information is a tool within a prejudiced assault on modal choice. As such, it was suggested that the government, or a government agency, would be an inappropriate supplier of this service.

It emerged quickly and strongly that the information provided was incomplete for participant needs. Financial cost and duration, whilst important, are not the sole mode-defining factors and the modal choice can, for some travellers, be more influenced by the convenience of each mode. Participants suggested that the convenience of the car is not adequately represented in the 'costs' given in visual aid 1 and that the convenience of travel by car is such that it negates the financial benefits of travel public transport. It was suggested that information including timetable information, return times, frequency of service and the location of the public transport interchange in relation to the origin and destination, could help the user to determine the 
convenience of the mode. This information could also help to assuage other (reasoned) concerns that lie at the root of modal choice. For example, information about the frequency of services not only indicates convenience but can challenge perceptions of the inflexibility of public transport, providing a form of insurance against the perceived unreliability of public transport; information about earlier and later services can help to give confidence in public transport and to make travel by a non-car mode appear to be less of a risk.

\section{Visual aid 2}

Visual aid 2 (Figure 3), gave more detailed information than visual aid 1, but for the same journey. The information given included financial cost, journey duration, departure and arrival times, route information for travel by car and taxi information for the journeys by coach and train.

Figure 3 inserted here.

Reactions to visual aid 2 were less subjective than reactions to visual aid 1 and comments were more reasoned, relating more to the information itself than to more emotive factors. It appears that participants were affected by increased exposure to the concept of modal change and of IMTI, feeling more comfortable with the concept and therefore feeling more positive towards the subject area. A consideration of the potential causes of this and the impacts upon the validity of the research is expanded upon in the discussion section of this paper.

Participants suggested that some of the concerns detailed above in reaction to visual aid 1 were addressed by visual aid 2. In particular, the additional information addressed, to an extent, 
concerns about insecurity, reliability and convenience. Making a journey by public transport can be a daunting experience, particularly for travellers not used to using these modes. Travellers can feel uncertain, alone, nervous - and foolish, if they do not know, for example, where their bus stop is, or how to read a timetable. These feelings are not experienced during travel by car in an environment in which the traveller can feel cocooned and isolated from harm. It emerged that information presented in visual aid 2 could help to allay some fears, increasing confidence in the ability to complete a journey by public transport safely and with minimal inconvenience. In particular, participants suggested that the provision of telephone numbers for taxi companies provides a security 'safety net' for travel by public transport, providing an alternative, just in case, whilst also facilitating completion of the journey from door to door, helping to increase traveller confidence, alleviating feelings of nervousness and easing uncertainty. Furthermore, participants suggested that the inclusion of information regarding the frequency of public transport services could help to increase their confidence in the convenience of services, whilst also providing reassurance that if a service is cancelled, or missed, an alternative is available. This also increases the perceptions of the flexibility of public transport, allowing the traveller to be more flexible in their departure times and allowing travellers to structure transport plans around their day, rather than their day around the transport.

Further comments about the information in visual aid 2 centred around concerns about comfort. It was suggested that the information did little to address perceptions that travel by public transport is uncomfortable and that perhaps information about on board facilities could be provided. Information about safety and security on board and at the interchange was also requested. Finally, participants naturally focussed more upon the information about travel by train and coach than by car. Comments about the car-based information centred upon surprise at 
the full cost of car travel. However, whilst many participants expressed concern about the 'full' cost of travel by car, it emerged that raised awareness is unlikely to prompt a modal change. Rather, this awareness may dissuade the traveller from considering an alternative mode, because the cost of car travel is seen to be 'pre-paid', therefore, travellers will use the car in order to get their money's worth. In this sense, the 'full' cost of travel by public transport is seen to be the ticket price plus the pre-paid cost of the car - and, therefore, to be prohibitively expensive.

\section{Visual aid 3}

Participants were given a third visual aid (Figure 4), showing more detailed information than given in visual aids 1 and 2, for the same journey. The information included road works and congestion information for the journey by car, including warnings that delays were possible; facilities information, both on board and at the interchange, for travel by coach and train; and alternative ticket prices for travel by coach and train.

Figure 4 inserted here.

Visual aid 3 provided much of the information that had been requested by participants in the earlier discussions. Concerns about the comfort of journeys by public transport were addressed to an extent by the provision of information about the facilities on board. As a result, many participants suggested that travel by public transport was a (more) valid modal option. In addition, this information suggests that public transport is able to meet the individual needs of the traveller, increasing the attractiveness of public transport and competing with perceptions regarding the comfort of the car. Whilst the information about earlier train and coach services 
was welcomed, the need for information about a number of earlier and later services, including information about the return journey, was again emphasised. In addition to increasing the flexibility and convenience of the journey and the confidence of the traveller, participants suggested that this would enable the traveller to feel more in control of the journey.

In discussing visual aid 3, participants returned to two key concerns about public transport, vis-à-vis the car: completion of the journey from door to door; and the necessity of trip chaining. The information for travel by coach and train failed to address either of these concerns and more personalised information to cover the door to door journey was requested. It emerged also that that in many instances people are not making straightforward outbound and return trips and engaging in a single activity. Rather, they are undertaking trip chains and participating in multiple activities. This introduces further information needs, concerning their travel choices and trip planning. Door to door and trip chaining information could provide a truer picture of the utility of each mode.

It had been expected that information about road works and delays could decrease perceptions of the convenience, speed, comfort and reliability of travel by car and prompt consideration of modal change. Whilst this was true for some participants, it was not universally the case. Rather, the information would help some drivers to travel by car more effectively, allowing them to avoid disruption by planning an alternative route in advance. Information about road works and delays may prompt a modal change only if the predicted stress associated with congestion and diversions were to reduce the perceptions of the comfort and convenience of travel by car and if the perceived disbenefits of travel by public transport were then seen to decrease proportionally, vis-à-vis the car. 


\section{Perceived effects of the information}

In discussing the effects of the information, participants were divided as to the extent to which the information would, or would be likely to, prompt a modal change, an attitudinal change, or have no effect at all. It can be suggested that approximately a fifth of respondents would fall into the latter category, feeling that the information would be entirely superfluous to their needs and that they would be unlikely to consult the information. Even if their current mode of transport, the car, were temporarily out of action, these participants felt that they would employ coping mechanisms, which excluded consideration of public transport, including car sharing and car hire.

The majority of participants felt that the information could prompt and, indeed, had prompted, during the course of the discussion, an attitudinal change, with the result that they may feel, or, indeed, felt, more predisposed to the concept of travel by alternative modes. This group would be likely to consult the information when the decision to consider a modal choice had been made. They may also consult the information to consider the alternatives for journeys made regularly, to discover whether their current mode was the optimal choice for their journey. The information would be of particular use for this group if their current mode of transport were temporarily unavailable. Following discussion and presentation of information options, this group was willing to consider alternative modes - but their use of the information would be sporadic, informed largely by the trip type: non-habitual trips, or those with suitable characteristics.

Approximately a fifth of participants felt that they would consult this information to make a modal choice, for a large number of journeys. For this group, raised awareness of and easy access to information about alternatives could be enough to persuade a modal change, 
removing as it does this key barrier to their use of non-car modes and making travel by public transport simpler and, as a result, more attractive.

It takes the donkey work out of it, doesn’t it? Phoning up everybody.

\section{DISCUSSION}

The discussion section of this paper focuses upon four issues raised by these results. Firstly, the importance of information in modal choice. Secondly, the likely demand for IMTI. Thirdly, the likely effect of this information. Finally, this section will discuss the validity of the survey method and, thus, the reliability of the results.

The results suggest that, currently, information plays a minor role in modal choice (as distinct from the role it plays in journey planning and execution for a chosen mode). The habituality of activities and thus trip types and, within this, of modal choice, with a strong modal identity being ascribed to both the trip and the person, contribute towards the lack of consideration, by the majority of participants, of their modal choice. Even where the individual is to undertake a new journey, the habituality of modal identity is such that modal alternatives to the primary mode are rarely considered. Alongside this, reasoned and subjective perceptions combine to further reduce both the likelihood of consideration of alternative modes and, in consequence, the probability that the traveller will consult information. The more reasoned attitudes are seen, by the traveller, as knowledge - for example, participants 'know' that travel by public transport is uncomfortable, unsafe or inconvenient, despite not having travelled by or enquired about public transport - and their subjective attitudes as 'truths', each of which reduce demand for information. It would also appear that the strength of both subjective and reasoned attitudes are related to modal experience, which is in turn related to habit. Thus, the three factors 
interact upon and influence each other and should not be seen as separate factors influencing modal choice. Low awareness of information sources and the perception that accessing traveller information is difficult and time consuming further compounds its low use. Thus, on the basis of the results, we can confidently suggest that at present, the use of MTI and UTI to inform a modal choice appears to be slight.

Analysis of reactions to the integrated multimodal traveller information suggests that, where this information is consulted, it may be more effective in informing a modal choice than is existing MTI or UTI. The information performs two primary roles. Firstly, an informative role, both informing the user about the journey about which they have enquired, whilst also informing the user that alternatives exist, before informing them about these alternatives. In this latter sense, the integration of the information can overcome two of the four identified barriers to information use - awareness of sources of information for each mode and the effort involved in accessing and comparing these sources. Secondly, the information appears to perform a challenging role, tackling assumed 'knowledge' and 'truths', the attitudes towards each mode. The extent to which the information will succeed in challenging these attitudes is, in turn, dependent upon the information that is provided. The results suggest that the information must seek to inform the user about 'softer' options, including comfort and convenience, as well as the more commonly requested factors of cost and journey duration. In addition, such information can help to tackle subjective perceptions, alongside information which subtly suggests the flexibility and individuality of public transport, or the existence of safety nets for travel by otherdependent modes.

Whilst the results do much to suggest that where IMTI is consulted, it could produce a modal shift, amongst some users, a number of notes of caution should be sounded. There is 
much in the results that can question the impact of IMTI. Firstly, the likely demand for IMTI is uncertain. Three of the four identified barriers to traveller information use - awareness of use of information, of types of information available and of sources of information - may continue to affect consideration of information. IMTI continues to rely upon the traveller seeking to use information, or to use an alternative mode - but the results suggest that these scenarios occur at low frequency. In addition, IMTI relies upon travellers being receptive to the information, on a number of levels: they will welcome the information; they will consider each of the modal options; they will make a rational choice between each option; and that they will consider a modal shift to public transport. However, previous studies have illustrated that rationality in modal choice is uncommon. Initial discussions in this study uncovered a degree of hostility to the concept of and suspicion of the motives behind modal challenge, amongst many car-driving participants, which could have an effect upon effective and repeated use of the service. The results also suggest that the information may not necessarily promote a modal shift towards public transport, acting instead to reinforce, persuade, or enable the traveller to make more efficient their car use, as the full, pre-paid cost of car ownership is realised. Further disaffection with the service may be prompted by almost certain difficulties in providing the level of detail demanded and accuracy expected, particularly in relation to the provision of door to door information and that which allows trip chaining. Effective marketing of IMTI in addressing each of these concerns will be crucial, to raise awareness, encourage (continued) use and to emphasise the modal impartiality of the service.

Finally, the results must be judged alongside consideration of a number of methodological constraints. The study took a qualitative approach, to allow discussion of attitudes towards modal change and exploration of responses to the information presented to a 
depth that could not be achieved through more quantitative methods, which by their nature employ more restrictive and prescriptive methods of questioning. In addition, the research undertook to explore a concept and to make recommendations for further research in this area. Whilst it is felt that the use of this methodology is appropriate to achieve these stated aims, some concerns regarding reliability exist. It can be suggested that the reactions of participants to the information may have been coloured and that, as such, the attitudinal effects witnessed may not be attributable to the information. The discursive process itself could have influenced attitudes, out with the information. As participants found their views challenged through debate, their opinions may have altered through reasoned consideration, or have only temporarily changed through, or been suppressed as a result of, peer pressure. Whilst the latter is considered to be unlikely, the former two cannot be dismissed and as such the reader may question the role of the information in attitudinal change. A second consideration concerns the repeated exposure of participants to information. The softening of participants' attitudes as a result of recurring exposure cannot be overlooked - and, indeed, this has been identified as a positive attribute of repeated use of the proposed IMTI system. However, the extent to which increasingly positive reactions to the information can be attributed to the increasing detail presented, rather than merely to repeated exposure, must be questioned. Finally, the information presented showed each mode as equally viable and it should be recognised that different results will be gained where the journeys shown are perhaps highly deviant in their viability.

As such, the authors implore the reader to reflect upon these questions in their consideration of the above results. Having explored, theoretically, the concept of integrated multimodal traveller information, the authors urge further research, focussing upon 
implementation of IMTI, to allow assessment of the acceptance, use and effects of such an information system upon different categories of traveller, in real-life conditions.

\section{ACKNOWLEDGEMENTS}

This paper stems from research commissioned by the UK Highway's Agency to assess the merits of combining the provision of highway information with public transport information and, more particularly, to assess the potential benefits and challenges associated with IMTI provision. The authors wish to acknowledge the support of the Highways Agency, which has enabled research in this field to be progressed. However, the views expressed in this paper remain those of the authors and do not necessarily reflect those of the Highways Agency. The authors wish to express thanks for the helpful comments of anonymous reviewers of initial drafts of this paper, which have allowed a more balanced account of the research to be presented. 


\section{REFERENCES}

Aarts, H., Verplanken, B. and van Knippenberg, A. (1997). Habit and Information Use in Travel Choices. Acta Psychologica. 96 1-14.

Abdel-Aty, M.A., Kitamura, R. and Jovanis, P.P. (1996). Investigating Effect of Advanced Traveler Information on Commuter Tendency to Use Transit. Transportation Research Record. 1550, 65-72.

Adler, J.L. and Blue, V.J. (1998). Toward the Design of Intelligent Traveler Information Systems. Transportation Research C, 6, 157-172

Aird, A. (1972). The Automotive Nightmare. London: Hutchinson and Co.

DETR. (1998). A New Deal for Transport: Better for Everyone, Transport White Paper. London: TSO.

DETR. (2000). Transport 2010: The 10 Year Plan. London: TSO.

Egeler, C. (2001). Multimodal Travel Information Service for Transport in the Tri-National Agglomeration of Basel Based on Real Time Data. Proc. $1^{\text {st }}$ Swiss Transport Research Conference. Ascona, Switzerland. March 1-3 2001.

Everett, P.B. and Watson, B.G. (1991). Psychological Contributions to Transportation. In Stokols, D. and Altman, I. (eds) Handbook of Experimental Psychology Volume 2, Florida: Krieger Publishing Co.

Flink, J. (1975). The Car Culture. Cambridge MA: MIT Press.

Freund, P. and Martin, G. (1993). The Ecology of the Automobile. Montreal: Black Rose Books Gartman (1994). Auto Opium. London: Routledge. 
Gillam, T., Lyons, G., and McDonald, M. (1999). Traveller Information Systems: What Do End Users Really Want? Proc. European Transport Conference, Cambridge, UK, September. $329-341$.

Harris, P. and Konheim, C.S. (1995). Public Interest In, and Willingness to Pay For, Enhanced Traveler Information as Provided By IVHS in The New York Metropolitan Area. Proc. 5th Annual Meeting of ITS America, 1, March, 247-251.

INFOPOLIS (1999) Needs of Travellers: An Analysis Based on the Study Of Their Tasks and Activities. http://www.ul.ie/ infopolis/pdf/info2_del3.pdf, current 14/05/02.

Kenyon, S.L., Bennett, L.D. and Cassidy, S. (2000). The User’s Utopia: User Testing of Internet Based Transport Information. Proc. RTIC 2000, London, April, 46-50.

Kenyon, S., Lyons, G. and Austin, J. (2001). Public Transport Information Websites: How to Get It Right. A Best Practice Guide. London: The Institute of Logistics and Transport.

Lappin, J. (2000). What We Have Learned About Advanced Traveler Information Systems and Customer Satisfaction. In Sussman, J. (2000). What Have We Learned About Intelligent Transportation Systems? Washington: FHWA. 65-86.

Lyons, G.D. (2001). From Advanced Towards Effective Traveller Information Systems. In Hensher, D. (Ed). Travel Behaviour Research: The leading edge. Pp 813-826. London: Pergamon.

Lyons, G., Harman, R., Austin, J. and Duff, A. (2001). Traveller Information Systems Research: A review and recommendations for Transport Direct. Available at: http://www.dtlr.gov.uk/itwp/transdirect/travinfo/index.htm, current 15/04/02. 
Mehndiratta, S.R., Kemp, M.A., Lappin, J. and Brand, D. (1999). What Advanced Traveler Information System Information Do Users Really Want? Transportation Research Record 1679. 41-49.

Neuherz, M. et al (2000). User Acceptance and Impacts of New Multimodal Traffic Information Services in BAYERNINFO. Proc. 7th ITS World Congress. Turin, Italy. 6-9 November 2000.

Ortuzar, J. de D. and Willumsen, L.G. (1994). Modelling Transport. Chichester: Wiley.

Potgraven, P.J.G. and van Leusden, G.C.J.M. (1995). The Realisation of a Multimodal Travel Information System in The Netherlands. Proc. 2nd World Congress on ITS, 2, Yokohama, November, 730-734.

Sachs, W. (1992). For Love of the Automobile. Oxford: University of California Press.

Schultz, H-J., Bolelli, A., Mouline, E. and Klassen, N. (1999). INFOTEN: Multimodal Information and Traffic Management Systems on Trans-European Networks. http://www.infoten.com/HTML/Report/d10.pdf, current 14/05/02.

Steg, L. and Vlek, C. (1997). The Role of Problem Awareness in Willingness-to-Change Car Use and in Evaluating Relevant Policy Measures. In Rothengatter, J.A., Carbonell Vaya, E. (Eds.). Traffic and Transport Psychology. Oxford: Pergamon Press.

Steg, L., Vlek, C. and Slotegraaf, G. (2001). Instrumental-reasoned and Symbolic-affective Motives For Using a Motor Car. Transportation Research F. 4, pp151-169.

Stradling, S.G. (2002). Transport User Needs and Marketing Public Transport. Municipal Engineer: Special Issue on Sustainable Transport Policy.

Tertoolen, G., van Kreveld, D. and Verstraten, B. (1998). 'Psychological Resistance Against Attempts to Reduce Private Car Use’. Transportation Research A. 32:3, pp171-181 
Thorgersen, J. (2001). Structural and Psychological Determinants of the Use of Public Transport. TRIP Colloquium, 14-15 November 2001. Horsholm, Denmark. http://www.akf.dk/trip/publications/papers/jt_public_tr.doc, viewed 18/08/02.

Transportation Research Group (2000). Establishing User Requirements from Traveller Information Systems. Final Report to the Engineering and Physical Sciences Research Council. Unpublished.

TRIP. (nd). Breaking the habitual choice of the private car. http://www.akf.dk/trip/projekter/14proj.pdf, current 14/05/02.

URS Thorburn Colquhoun, Jill Watkinson Research and Marketing Services and Business and Market Research. (2001). Transport Choices of Car Users in Rural and Urban Areas: a research study for DETR. Unpublished.

Verplanken, B., Aarts, H., and van Knippenberg, A. (1997). Habit, Information Acquisition and the Process of Making Travel Mode Choices. European Journal of Social Psychology. 27, 539-560.

Wright, C. and Egan, J. (2000). De-marketing the Car. Transport Policy. 7, pp287-294.

Yim, Y.B., Hall, R. and Weissenberger, S. (1996). Travinfo Evaluation: Traveler Response Element Broad Area Study. PATH working paper UCB-ITS-PWP-97-9. Unpublished.

Yim, Y.B., Koo, R. and Ygnace, J.L. (1998). Travinfo Evaluation: a study of transit information callers. Proc. ITS America, Detroit, Mich. CD-ROM. 


\section{FIGURES/TABLES}

Table 1. Participant profile.

Fig. 2. IMTI visual aid 1

Fig. 3. IMTI visual aid 2

Fig. 4. IMTI visual aid 3

Fig. 1. Process, in part subconscious, leading to information access 


\begin{tabular}{|c|c|c|c|c|c|}
\hline $\begin{array}{l}\text { Number of } \\
\text { Participants }\end{array}$ & Mode & Journey type & Gender & Age & Location \\
\hline 8 & $\begin{array}{l}2 \text { public transport only; } 6 \\
\text { able to drive and with } \\
\text { access to a car, may also } \\
\text { use public transport }\end{array}$ & $\begin{array}{l}\text { All must make } \\
\text { local and long } \\
\text { journeys } \\
\text { regularly }\end{array}$ & $\begin{array}{l}\text { Evenly } \\
\text { mixed }\end{array}$ & $\begin{array}{l}60+\text {, all } \\
\text { retired }\end{array}$ & $\begin{array}{l}\text { Winchester. } \\
\text { Cathedral city } \\
\text { Rural area }\end{array}$ \\
\hline 8 & $\begin{array}{l}\text { dedicated public } \\
\text { transport users (of whom } \\
\text { at least } 1 \text { will not drive); } 4 \\
\text { dedicated car users }\end{array}$ & No specification & $\begin{array}{l}\text { Evenly } \\
\text { mixed }\end{array}$ & $26-40$ & $\begin{array}{l}\text { Salisbury } \\
\text { Market town } \\
\text { Rural area }\end{array}$ \\
\hline 6 & $\begin{array}{l}4 \text { dedicated public } \\
\text { transport users (of whom } \\
\text { at least } 1 \text { will not drive); } 4 \\
\text { dedicated car users }\end{array}$ & No specification & $\begin{array}{l}\text { Mixed (2 } \\
\text { male, } 4 \\
\text { female) }\end{array}$ & $41-60$ & $\begin{array}{l}\text { Newark } \\
\text { Market town } \\
\text { Semi-urban }\end{array}$ \\
\hline 8 & $\begin{array}{l}1 \text { public transport only; } 7 \\
\text { able to drive and with } \\
\text { access to a car }\end{array}$ & $\begin{array}{l}4 \text { travelling } \\
\text { regularly with } \\
\text { children under } \\
12 ;\end{array}$ & Female & $25-50$ & $\begin{array}{l}\text { Newcastle } \\
\text { Upon Tyne } \\
\text { Large urban } \\
\text { conurbation }\end{array}$ \\
\hline 8 & $\begin{array}{l}1 \text { public transport only; } 7 \\
\text { able to drive and with } \\
\text { access to a car }\end{array}$ & $\begin{array}{l}4 \text { travelling } \\
\text { regularly with } \\
\text { children under } \\
12 ;\end{array}$ & Male & $25-50$ & $\begin{array}{l}\text { Manchester } \\
\text { Large urban } \\
\text { conurbation }\end{array}$ \\
\hline 6 & $\begin{array}{l}2 \text { public transport only; } 4 \\
\text { able to drive and with } \\
\text { access to a car }\end{array}$ & $\begin{array}{l}\text { All must make } \\
\text { long and short } \\
\text { journeys } \\
\text { regularly }\end{array}$ & $\begin{array}{l}\text { Evenly } \\
\text { mixed }\end{array}$ & $18-25$ & $\begin{array}{l}\text { Bristol } \\
\text { Small city } \\
\text { rural outposts }\end{array}$ \\
\hline
\end{tabular}

$\underline{\text { Table 1. Participant profile }}$ 
Figure 2. Visual Aid 1.

I need to travel from Bristol to Cardiff

to arrive at 11.00 on Friday 21 July 2000

\begin{tabular}{|l|l|l|}
\hline \multicolumn{3}{|l|}{ Bristol to Cardiff to arrive 11:00 21/7/00 } \\
\hline Mode & Duration (hh:mm) & Cost \\
\hline Car & $00: 59$ (estimate only) & $\begin{array}{l}\text { Fuel } £ 8.30 \text { return. Full cost: } \\
£ 19.20 \text { return (estimate only). } \\
£ 1 \text { per hour parking }\end{array}$ \\
\hline Train & $00: 48$ & $\begin{array}{l}£ 7.00 \text { day return (discounts } \\
\text { available for card holders) } \\
\text { Co.00 day return (discounts } \\
\text { available for card holders) }\end{array}$ \\
\hline
\end{tabular}


Figure 3. Visual Aid 2.

\section{I need to travel from Bristol to Cardiff to arrive at 11.00 on Friday 21 July 2000}

\section{BY CAR}

From: $\quad$ BRISTOL

To:

CARDIFF

Duration: $00: 59 *$

Distance: 41.6 Miles
*Estimated duration only - delays possible according to time of travel and current road conditions

Estimated costs: Fuel $£ 8.30$ return. Full cost: $£ 19.20$ return. Parking: $£ 1.00$ per hour

\section{BY TRAIN}

From: BRISTOL Temple Meads To: CARDIFF

Depart: 10:05
Arrive: $10: 53$

\author{
Road Route \\ A4 Avonmouth (Portway Roundabout) \\ M5M49 Motorway M5 \\ M49 Junction with M4 \\ M4 Junction 29 (A48(M)) \\ A48(M) Junction with A48 \\ A48 Junction with A4161 \\ A4161 CARDIFF
}


Figure 4. Visual Aid 3.

\section{I need to travel from Bristol to Cardiff to arrive at 11.00 on Friday 21 July 2000}

\section{BY CAR}

From: BRISTOL

To: CARDIFF

\section{Estimated costs:}

Fuel $£ 8.30$ return. Full cost: $£ 19.20$ return

Parking: $£ 1.00$ per hour

Known Traffic Problems No reported incidents

\section{Known Long Term Roadworks}

M4 eastbound Severn Crossing to Swindon at Junction 16 roadworks. Long delays.
*Estimated duration only - delays possible according to time of travel and current road conditions

Est. Duration: 00:59*

Distance: 41.6 miles

Depart: $10: 00^{*}$

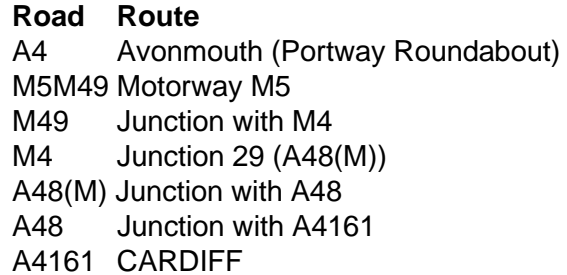

En route facilities - details available

*Allow extra time for journey. From: BRISTOL Temple Meads To: CARDIFF

BY TRAIN

Season Ticket:

1 week: $£ 42.30$

( $£ 8.46$ per day*)

1 month: $£ 162.50$

(£8.13 per day*)

*assumes regular

peak daily commute
Duration: 00:48

Earlier Train:

Duration 00:42

Depart: 10:05

Arrive: $10: 53$

Cost: $£ 7.00$ Day return (off peak but travelling Friday) $£ 9.60$ peak time travel. Apex advance: not available Discounts available for card holders

On board

facilities:

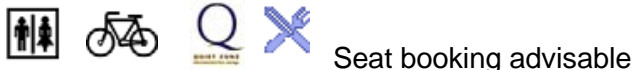

Alpha Bus: 02920490000 New Cabs: 02920811118 Central Taxis: 02920666333

\section{BY COACH}

From: BRISTOL

Marlborough Street Bus Station

Depart: 09:25

On board

facilities:
To: CARDIFF

Wood Street Bus Station

Arrive: 10:35
Duration: 01:10

Cost: $£ 6$ day return Discounts available for card holders 

Figure 1. Process, in part subconscious, leading to information access.

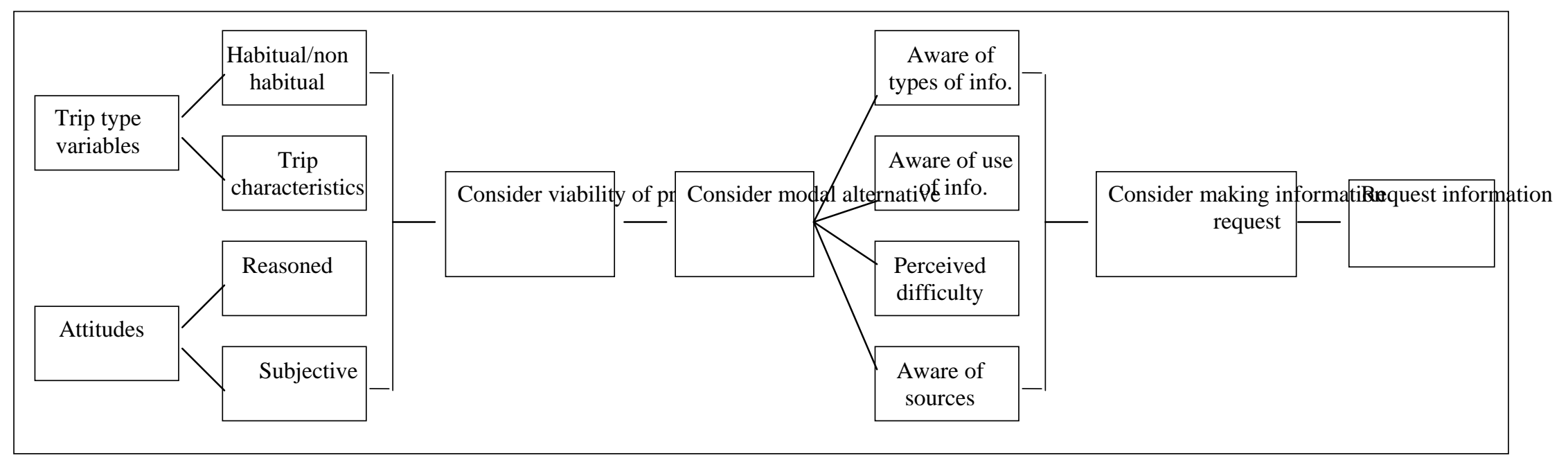

